\title{
Efficacy of Turmeric Extracts and Curcumin for Alleviating the Symptoms of Joint Arthritis: A Systematic Review and Meta-Analysis of Randomized Clinical Trials
}

\author{
James W. Daily, Mini Yang, and Sunmin Park ${ }^{2}$ \\ ${ }^{1}$ Department of R\&D Daily Manufacturing, Inc., Rockwell, North Carolina, USA. \\ ${ }^{2}$ Department of Food and Nutrition, Obesity/Diabetes Research Center, Hoseo University, Asan, South Korea.
}

\begin{abstract}
Although turmeric and its curcumin-enriched extracts have been used for treating arthritis, no systematic review and meta-analysis of randomized clinical trials (RCTs) have been conducted to evaluate the strength of the research. We systemically evaluated all RCTs of turmeric extracts and curcumin for treating arthritis symptoms to elucidate the efficacy of curcuma for alleviating the symptoms of arthritis. Literature searches were conducted using 12 electronic databases, including PubMed, Embase, Cochrane Library, Korean databases, Chinese medical databases, and Indian scientific database. Search terms used were "turmeric," "curcuma," "curcumin," "arthritis," and "osteoarthritis." A pain visual analogue score (PVAS) and Western Ontario and McMaster Universities Osteoarthritis Index (WOMAC) were used for the major outcomes of arthritis. Initial searches yielded 29 articles, of which 8 met specific selection criteria. Three among the included RCTs reported reduction of PVAS (mean difference: $-2.04[-2.85,-1.24])$ with turmeric/curcumin in comparison with placebo $(P<.00001)$, whereas metaanalysis of four studies showed a decrease of WOMAC with turmeric/curcumin treatment (mean difference: -15.36 [ -26.9 , -3.77]; $P=.009$ ). Furthermore, there was no significant mean difference in PVAS between turmeric/curcumin and pain medicine in meta-analysis of five studies. Eight RCTs included in the review exhibited low to moderate risk of bias. There was no publication bias in the meta-analysis. In conclusion, these RCTs provide scientific evidence that supports the efficacy of turmeric extract (about $1000 \mathrm{mg} /$ day of curcumin) in the treatment of arthritis. However, the total number of RCTs included in the analysis, the total sample size, and the methodological quality of the primary studies were not sufficient to draw definitive conclusions. Thus, more rigorous and larger studies are needed to confirm the therapeutic efficacy of turmeric for arthritis.
\end{abstract}

KEYWORDS: • arthritis $\bullet$ curcuma $\bullet$ osteoarthritis $\bullet$ pain visual analogue score $\bullet$ systematic review $\bullet$ turmeric

\section{INTRODUCTION}

$\mathbf{T}$ HE TERM ARTHRITIS is derived from the Greek words "artho" and "itis," meaning joint and inflammation, respectively. Arthritis is a form of joint disorder characterized by chronic inflammation in one or more joints that usually results in pain and is often disabling. ${ }^{1,2}$ Arthritis includes more than 100 different forms: the most common form is osteoarthritis, but other forms include rheumatoid arthritis, psoriatic arthritis, and related autoimmune diseases. ${ }^{1,2}$ Although the causes of these diseases are different, their symptoms and treatments are similar. As osteoarthritis is a degenerative joint disease, the number of people with arthritis is also growing with the increase in the aging population. ${ }^{1}$ The worldwide prevalence

Manuscript received 30 March 2016. Revision accepted 12 July 2016.

Address correspondence to: Sunmin Park, PhD, Department of Food and Nutrition, Obesity/Diabetes Research Center, Hoseo University, 165 Sechul-Ri, BaeBang-Yup, Asan-Si 336-795, ChungNam-Do, South Korea, E-mail: smpark@hoseo.edu of knee osteoarthritis increased 26.6\% from 1990 to 2010, and it affects about $9.6 \%$ of men and $18 \%$ of women more than 60 years of age. ${ }^{3}$ The occurrence of osteoarthritis increases with age due to the decreased capacity to suppress inflammation, agerelated sarcopenia, and increased bone turnover. ${ }^{1}$ Rheumatoid arthritis is a systemic inflammatory and destructive joint disease with a prevalence of about $1-2 \%$ of the adult population worldwide. $^{2}$

Although arthritis is associated with inflammation and pain, the exact cause of arthritis remains uncertain, and there is no treatment for its fundamental causes. The major goal of arthritis treatment is to reduce joint pain induced by inflammation in the joints, daily wear and tear of joints, and muscle strains. ${ }^{4}$ The existing pharmaceuticals for treating arthritis are analgesics, steroids, and nonsteroidal antiinflammatory drugs (NSAIDs), which reduce the symptoms such as severe pain and inflammation. ${ }^{5}$ Classical NSAIDs are cyclooxygenase (COX) inhibitors that inhibit prostaglandin and thromboxane synthesis, thereby reducing inflammation. ${ }^{5}$

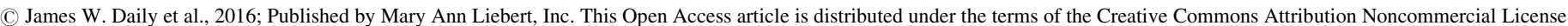

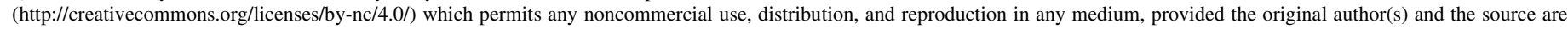
credited. 
New NSAIDs selectively inhibit COX-2 and are usually specific to inflamed tissue, which decreases the risk of peptic ulcer. ${ }^{5}$ However, their long-term use cannot be sustained due to inadequate pain relief, immune disturbances, and serious gastrointestinal and cardiovascular adverse events. ${ }^{6}$ Therefore, herbal therapies with anti-inflammatory properties and minimum side effects are needed for the treatment of arthritis, including rheumatoid arthritis and osteoarthritis, especially after the withdrawal of many Food and Drug Administration-approved anti-inflammatory drugs. ${ }^{7}$

Curcuma longa and Zingiber officinale, both of which belong to the Ziangiberaceae family, are potential alternative medicines for arthritis. ${ }^{8,9}$ They have been used as seasonings in many ethnic cuisines in various countries such as Bangladesh, India, and Pakistan. They have long been used as anti-inflammatory treatments in traditional Chinese and Ayurvedic medicines. ${ }^{10}$ The effective components of $Z$. officinale: gingerols, shogaols, zingerone, and paradol, and ginger itself have been reported to exert anti-inflammatory effects by inhibiting COX-1 and COX-2, nuclear factor kappalight-chain-enhancer of activated $\mathrm{B}$ cells $(\mathrm{NF}-\kappa \mathrm{B})$, and 5-lipoxygenase (5-LOX). ${ }^{11}$ Several systematic reviews of clinical trials have shown that ginger may reduce the subjective experience of pain in some conditions such as muscular diseases. ${ }^{12}$ In addition, turmeric extracts have activities similar to ginger although they have different effective compounds. Several studies have evaluated the efficacy of turmeric extracts for the treatment of musculoskeletal disorders. ${ }^{13}$

Although turmeric belongs to the Zingiberaceae family, turmeric contains different bioactive components, mainly curcumin and demethoxycurcumin, bis-demethoxycurcumin, and turmeric essential oils. When used as an alternative medicine or dietary supplement, turmeric is typically used as an extract that is standardized to $80-95 \%$ curcuminoids, primarily curcumin. Turmeric and its derivatives have antiinflammatory activities. Unlike ginger, turmeric and curcumin do not modulate COX-1 activity, ${ }^{14,15}$ but modify $\mathrm{NF}-\kappa \mathrm{B}$ signaling, proinflammatory cytokines such as interleukin production and phospholipase $\mathrm{A} 2, \mathrm{COX}-2$, and 5-LOX activities. Curcumin also modulates the expressions of various transcription factors involved in energy metabolism such as signal transducer and activator of transcription, peroxisome proliferator-activated receptor- $\gamma$, activator protein-1, cAMP responding element binding protein, estrogen response element, and others. ${ }^{15}$ As a result, turmeric and its components have been reported to exert beneficial effects on osteoarthritis, type 2 diabetes, and dyslipidemia. Turmeric is better tolerated than ginger and pepper due to being less hot and spicy. Therefore, it is important to conduct a systematic review of the antiarthritis effects of curcuma.

The purpose of this review was to systemically evaluate all randomized clinical trials (RCTs) of turmeric and curcumin for treating arthritis symptoms and to elucidate the efficacy of curcuma for alleviating the symptoms of arthritis. To the best of our knowledge, this is the first systematic review and meta-analysis of RCTs on the efficacy of turmeric for arthritis symptoms.

\section{METHODS}

\section{Data sources and selection criteria}

The following electronic databases were searched: PubMed, Embase, Cochrane Library, Korean databases such as DBpia, the Research Information Service System (RISS), the Korean Information Service System (KISS), Chinese medical databases such as China National Knowledge Infrastructure (CNKI) and the Chinese Scientific Journals Database, the Indian Medical Journals and the Indian Journals. Dissertations were also included. The search was conducted in the databases using proper languages of English, Korean, and Chinese. The following keywords of Medical Sub Headings (MeSH) were used as search terms: "curcumin," "curcuma," "turmeric," "Curcuma domestica," "Curcuma Longa," "arthritis," "osteoarthritis," "randomized," "controlled trial," and "clinical trial." In the systematic review, all RCTs were included from the available databases (as far back as 1966 in PubMed) up to April, 2016, that had examined the effects of turmeric (Curcuma) and curcumin on arthritis.

\section{Article evaluation and selection}

Two independent reviewers (J.W.D. and M.Y.) screened the articles. In the first screening, the related articles were identified by the titles and abstracts of the articles and the relevant articles were retrieved in full text and validated for inclusion in the systematic review. The third reviewer (S.P.) independently validated the selected articles.

\section{Eligibility criteria for studies used in this review}

All prospective randomized clinical studies using turmeric (C. longa and the synonym domestica) and curcumin for the treatment of arthritis were included in this systematic review. Exclusion criteria included in vitro studies, in vivo studies in nonhuman species, studies that were only published in abstract form or included insufficient data to properly evaluate the outcomes, nonclinical trial studies, and studies in which arthritis was not the primary outcome measured, and then we eliminated the duplicates. A flow diagram of the article selection process is shown in Figure 1. Although no language barriers were imposed, all studies included in this review were written in English. Dissertations about randomized clinical studies were also included.

\section{Subjects and intervention}

Subjects included in the studies were mostly middleage and elderly men and women, although the ages varied among the studies. Subjects were recruited with degenerative primary knee osteoarthritis ${ }^{16-23}$ and rheumatoid arthritis $^{24}$ with mild-to-moderate severity according to the American Rheumatism Association criteria. Subjects in most studies had pain scores $\geq 5$ of 10 on the numerical rating scale. ${ }^{25}$ Inclusion criteria are summarized by study in 


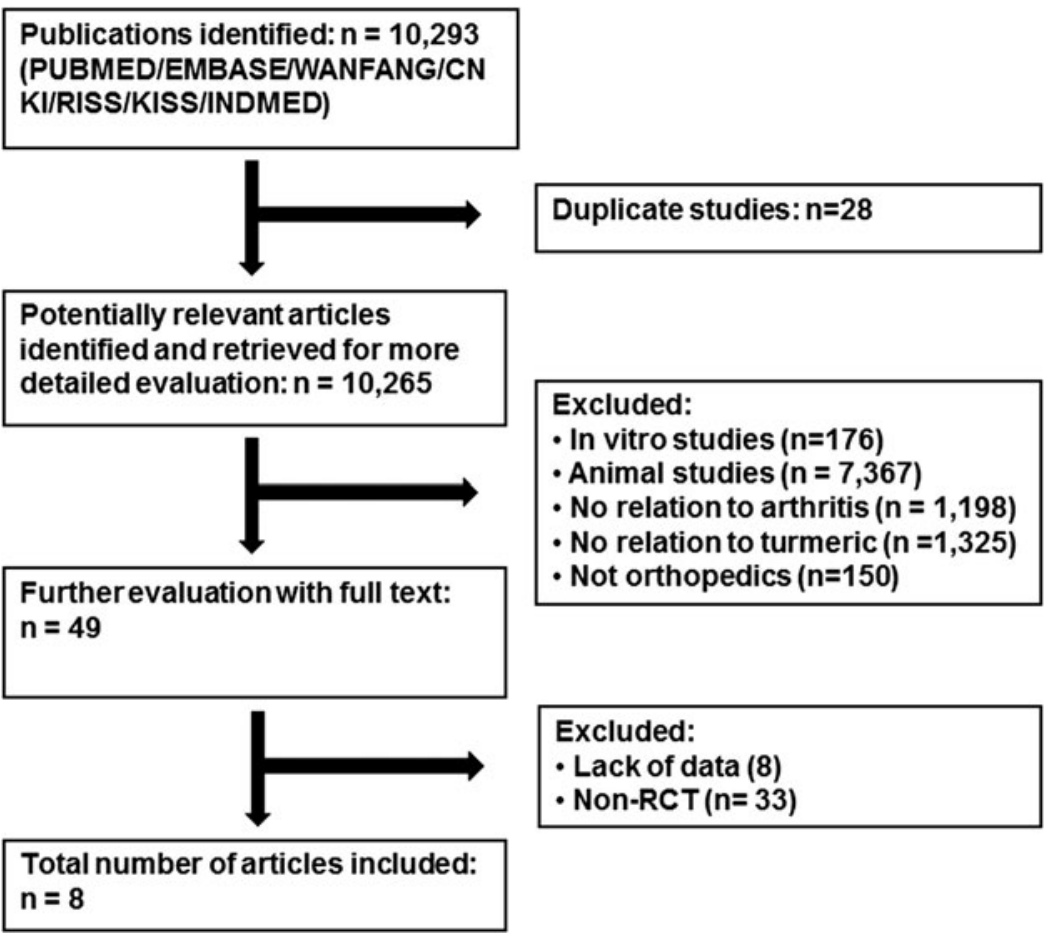

FIG. 1. Flowchart of the selection process of the randomized clinical trials for systematic review.

Table 1. Two studies did not include exclusion criteria. ${ }^{20,21}$ Exclusion criteria of subjects were somewhat different among the other studies but four studies excluded the patients who had conditions that would prevent the use of treatment protocols such as abnormal liver or renal function, history of peptic ulcer, allergy to curcumin, curcuminoids, or other drugs used in the study such as ibuprofen, diclofenac sodium, and glucosamine. ${ }^{16-18,24}$ Several studies excluded subjects with conditions that would interfere with the outcome assessments or act as confounders in the study, including secondary osteoarthritis, candidates for surgical joint replacement or any other surgical treatment, presence of heart, renal, and liver failure, using corticosteroids with doses more than $10 \mathrm{mg} /$ day during the preceding 3 months, history of psychological disorders, and intraarticular injections during the preceding 3 months. ${ }^{17,19,22-24}$ Other exclusions included pregnancy or lactation, ${ }^{19,23,24}$ body mass index $>25,{ }^{19,23}$ severe bone or joint deformity, ${ }^{23}$ history of infections resulting in hospitalization, ${ }^{24}$ recent use of antiinflammatory drugs, or abuse of drugs or alcohol. ${ }^{24}$ The subjects were instructed not to use any medications or herbs other than those provided by the study during the experimental periods.

The studies included in the systematic review utilized turmeric extracts and its components, mostly curcuminoids, and in one study polysaccarides, which were considered as the primary effective component for osteoarthritis. Ethanolic extracts of turmeric were used in two studies, ${ }^{16,18}$ and water extracts rich in polysaccharides were used in one study. ${ }^{22}$ In the remaining five studies, ${ }^{17,19-21,24}$ curcumin or curcumin-containing mixture was considered as treatments (Table 1).

\section{Outcome measures}

Osteoarthritis and rheumatoid arthritis have similar symptoms such as pain, tenderness, swelling, and stiffness. The severity of arthritis was determined by the Western Ontario and McMaster Universities Osteoarthritis Index $\left(\right.$ WOMAC) ${ }^{26}$ and pain visual analogue score (PVAS) ${ }^{27}$ for pain. WOMAC is a standardized index for the assessment of the severity of osteoarthritis symptoms. PVAS is a tool widely used to measure pain. The validity and reliability of WOMAC and PVAS have been established. ${ }^{26}$ WOMAC consisted of subclasses 5 items for pain, 2 items for stiffness, and 17 items for physical functioning. Each item was rated from 0 to 4 and the total scoring for pain, stiffness, and physical function was calculated by adding each item for the categories. However, one study ${ }^{22}$ measured only five items for pain. Subjects answered a perception of pain intensity on a $10 \mathrm{~cm}$ horizontal scale in the PVAS assessment and the severity was represented by the scores of $0-10$. In WOMAC and PVAS, a lower score indicated less severe symptoms. WOMAC for pain and PVAS were used as outcome measures for meta-analysis.

Other outcome measures used in the studies were to evaluate function of joints and stiffness when pain was determined by PVAS. In addition, pain associated with daily tasks such as running and walking upstairs, ${ }^{16,21,24}$ clinician global impression of change, ${ }^{22}$ and Lequesne's pain functional index (LPFI) ${ }^{17}$ was measured.

\section{Quality assessment of the articles}

The Cochrane tool was used to assess quality of the RCT articles included in this systematic review by determining 


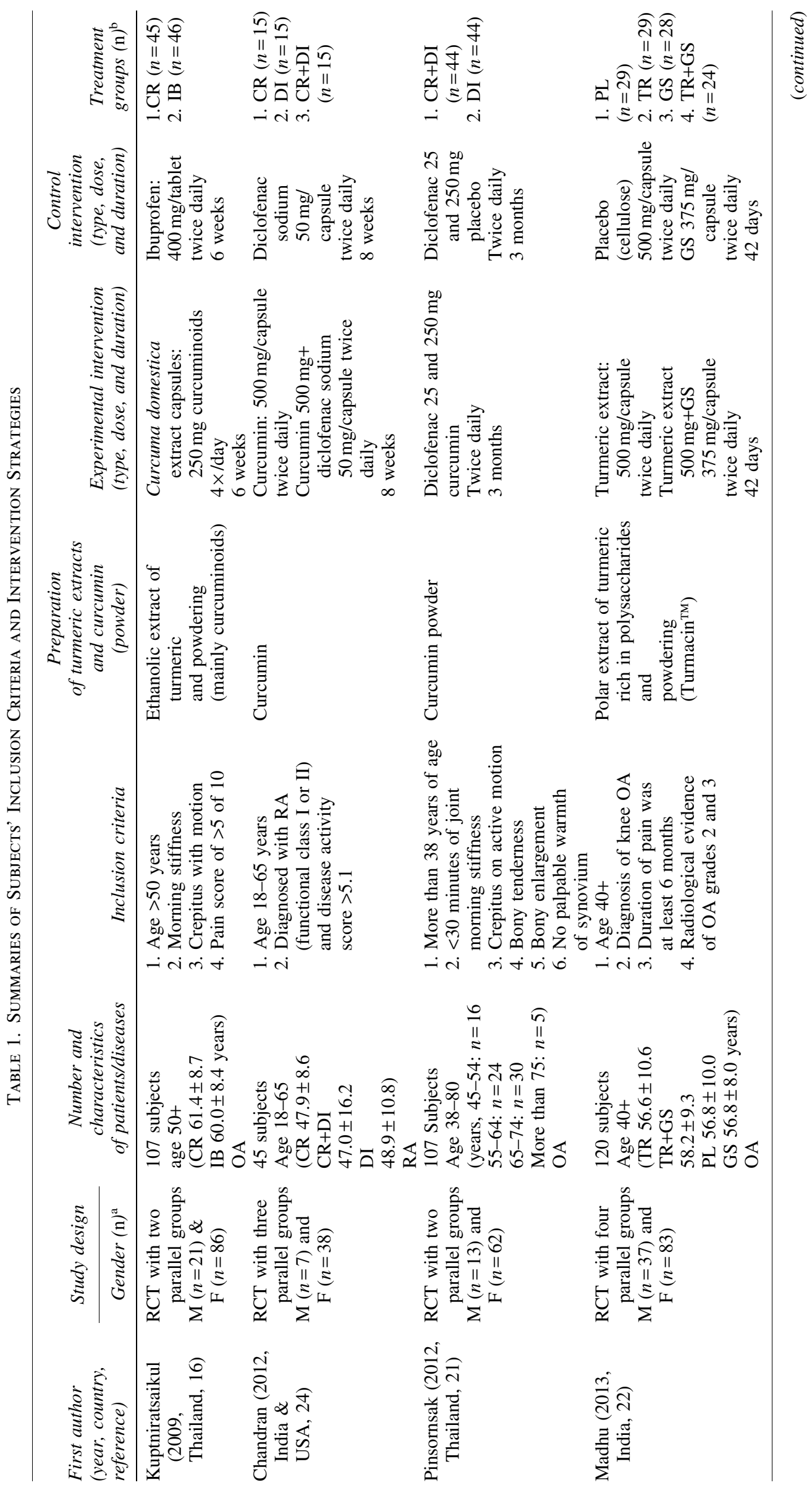




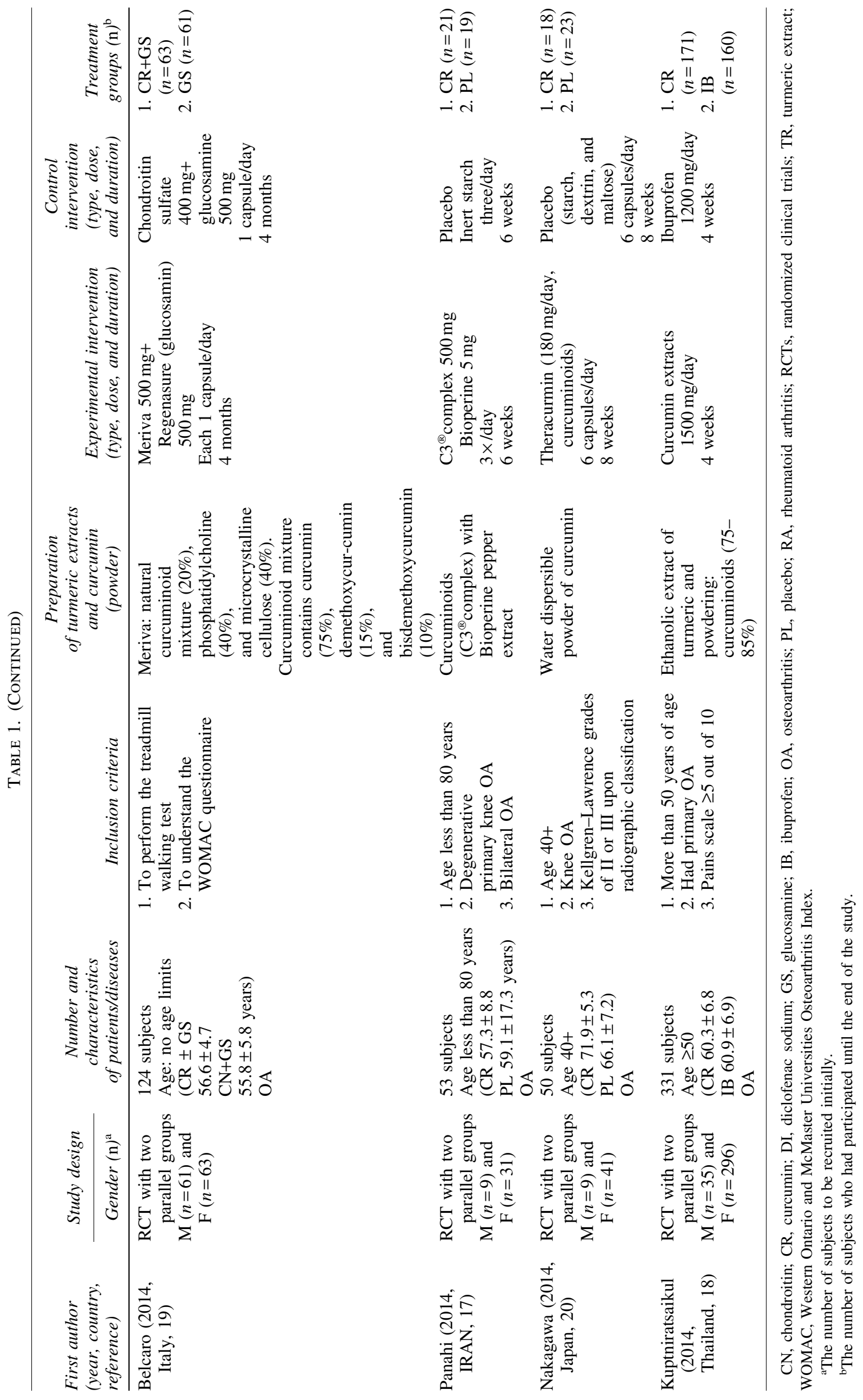


the risk of bias (ROB). ${ }^{28}$ This validated tool consists of the following eight categories: (1) random sequence generation, (2) allocation concealment, (3) blinding of participants, (4) assessor blinding, (5) reporting drop out or withdrawal, (6) intention to treat, (7) selective outcome reporting, and (8) other potential bias. Each category was scored as H, high ROB, U, uncertain ROB, or L, low ROB. Three independent reviewers (M.Y., S.P., and J.W.D.) performed the quality assessment, and disagreement on scores was resolved through discussion.

\section{Data analysis}

The data used for the meta-analysis were continuous variables of PVAS and arthritis symptoms (WOMAC for pain), and means and standard deviations were used for the meta-analysis. However, two studies ${ }^{20,21}$ were not included in the meta-analysis since they did not provide the means and standard deviations in the articles. Standard mean differences and 95\% confidence intervals (CIs) were calculated for a PVAS and WOMAC using the Cochrane Collaboration's software (RevMan Version 5.0 for Windows; The Nordic Cochrane Centre, Copenhagen, Denmark). Since the studies showed small variations in clinical heterogeneity between each study such as age, dose of curcuma, and treatment duration, the studies had low heterogeneity. However, in some meta-analysis, PVAS and WOMAC for pain were pooled together since both indexes presented the intensity of pain but their scales were different. When both indexes were pooled, random effect models were used. In addition, the heterogeneity was quantitatively confirmed with the heterogeneity analysis (Cochran's $Q$ ) of studies in meta-analysis. In the heterogeneity test, the heterogeneity of the included studies was considered to be low at $I^{2} \leq 25 \%$, moderate at $I^{2} \leq 50 \%$, high at $I^{2} \leq 75 \%$, and very high at $I^{2}$ $>75 \% .{ }^{29}$ When $I^{2}$ value was low, the fixed effect model was selected and otherwise the random model was used. The meta-analysis was conducted with data from parallel-group design studies between curcuma and placebo treatments or pain killer treatment. Funnel plots were used to detect reporting biases for this systematic review since the number of studies included was less than 10 .

\section{Subgroup analysis}

Eight studies were included in the systematic review, but all could not be included in the meta-analysis since their control groups were either placebo or pain killer, and the data formats were not matched with each other. Six studies provided means and standard deviation of PVASs ${ }^{16,17,20-22,24}$ whereas four studies gave those of WOMAC. ${ }^{17,18,22,23}$ Thus, six and four studies were included in the meta-analyses of PVAS and WOMAC, respectively. The subgroup analysis could not be done for this study. Fortunately, the dosage of curcumin or turmeric was similarly assigned among the studies: it was prescribed with about $1 \mathrm{~g} /$ day without giving other pain killers and about $500 \mathrm{mg} /$ day with pain killers. However, the experimental periods varied among the studies and ranged from 4 weeks to 4 months. It is better to conduct meta-analysis with subgroups according to short-term and long-term studies. Although the meta-analysis could not be performed according to the duration of the study, the adverse effects were reviewed with the duration of the study.

\section{RESULTS}

\section{Summary of included studies}

A total of 10,293 studies were found in the initial electronic searches from PubMed, Embase, WANFANG, CNKI, RISS, KISS, and IndMED, and 28 duplicates were removed. From the remaining 10,265 studies, those potentially not related RCT studies about curcumin and arthritis were removed and the details of the removed studies were as follows: 176 in vitro studies, 7367 animal experiments, 1198 no relation to arthritis, 1325 no relation to turmeric or curcumin, and 150 nonarthritis orthopedic-related studies (Fig. 1). Further evaluation of the full texts resulted in the elimination of 8 studies with lack of data and 33 studies due to non-RCT. Finally, eight RCTs met the inclusion criteria (Fig. 1). The eight RCTs were used for the systematic review. ${ }^{16-18,20-24}$ The subject characteristics and intervention strategies of the included RCTs are summarized in Table 1 and intervention results and adverse events are organized in Table 2.

Middle-age and elderly adults of both genders were mainly included in the selected studies (Table 1). Subjects in the selected studies had arthritis with either PVAS greater than 5 or with morning stiffness lasting less than 30 min, indicating moderate symptoms of osteoarthritis (Table 1). Subjects were excluded when they had the following problems: allergy to curcuminoids and pain killers such as ibuprofen that were used as the control group, secondary arthritis, current use of any immunotherapy, including corticosteroids, liver damage, serious chronic metabolic diseases other than arthritis such as diabetes, inflammatory disorders, heart, renal, and liver failure, and severe arthritis to be a candidate for surgical joint replacement.

Six of the studies were performed in Middle East and Asian countries and two studies were conducted in the United States and Italy as given in Table 2 . Six RCTs, ${ }^{16-21,23}$ one RCT, ${ }^{24}$ and one $\mathrm{RCT}^{22}$ had two-arm, three-arm, and four-arm parallel design, respectively. The three-arm parallel design study included the groups of curcumin only, curcumin+diclofenac sodium, and diclofenac sodium groups, and the four-arm parallel design study consisted of curcumin only, curcumin+glucosamine, glucosamine only, and placebo. Six RCTs contained curcumin powder and placebo groups ${ }^{17,20-24}$ and four studies used pain killers such as ibuprofen, diclofene, or glucosamine as a control group. ${ }^{16,18,22,24}$ The dosage of curcumin was varied in different studies within 100-2000 mg/day and the curcumin or turmeric was provided one to four times a day with up to $500 \mathrm{mg}$ per time. One study ${ }^{22}$ used a polysaccharide-rich extract that contained no curcumin (Table 2). 
Table 2. Summaries of Intervention Results and Adverse Events

\begin{tabular}{|c|c|c|c|c|c|c|c|}
\hline $\begin{array}{l}\text { First author } \\
\text { (year), } \\
\text { reference }\end{array}$ & $\begin{array}{c}\text { Intervention } \\
\text { dose \& } \\
\text { duration }\end{array}$ & $\begin{array}{c}\text { Main } \\
\text { outcomes for } \\
\text { meta-analysis }\end{array}$ & Treatment results & Control results & Other results & $\begin{array}{l}\text { Author's } \\
\text { conclusions }\end{array}$ & $\begin{array}{l}\text { Adverse } \\
\text { events }\end{array}$ \\
\hline $\begin{array}{l}\text { Kuptniratsaikul } \\
\text { (2009), } 16\end{array}$ & $\begin{array}{l}\text { Curcumin } \\
250 \mathrm{mg} \\
4 \times / \text { day } \\
6 \text { weeks }\end{array}$ & PVAS & $\begin{array}{l}\text { CR } 2.7 \pm 2.5 \\
P=.2\end{array}$ & $\begin{array}{l}\text { IB } 3.8 \pm 2.5 \\
P=.2\end{array}$ & $\begin{array}{l}\text { Pain on stairs } \\
\text { TR } 3.1 \pm 1.5 \\
\text { IB } 3.8 \pm 2.4\end{array}$ & $\begin{array}{l}\text { CR safe and } \\
\text { effective, } \\
\text { similar to IB }\end{array}$ & CR 1 , IB 3 \\
\hline $\begin{array}{l}\text { Chandran } \\
\quad(2012), 24\end{array}$ & $\begin{array}{l}\text { Curcumin } \\
\quad 500 \mathrm{mg} \text { or } \\
\text { DI } 50 \mathrm{mg} \\
2 \times / \text { day } \\
8 \text { weeks }\end{array}$ & PVAS & $\begin{array}{l}\text { CR } 27.5 \pm 9.4 \\
P<.05 \\
\text { CR+DI } \\
34.3 \pm 26.7, P<.05\end{array}$ & $\begin{array}{l}\text { DI } 39.2 \pm 20.1 \\
P<.05\end{array}$ & $\begin{array}{l}\text { CRP } \\
\text { CR } 5.34 \pm 4.12 \\
P<.05 \\
\text { CR+DI } \\
\quad 6.66 \pm 6.87 \\
\quad P>.05 \\
\text { DI } 3.35 \pm 2.5 \\
P>.05\end{array}$ & $\begin{array}{l}\text { Curcumin } \\
\text { provide } \\
\text { significant } \\
\text { improvement } \\
\text { for RA }\end{array}$ & $\begin{array}{l}\text { CR mild } \\
\text { throat } \\
\text { fever and } \\
\text { infection } \\
\text { DI itching, } \\
\text { eye } \\
\text { swelling } \\
\text { and dim } \\
\text { vision }\end{array}$ \\
\hline $\begin{array}{l}\text { Pinsornsak } \\
\quad(2012), 21\end{array}$ & $\begin{array}{l}\text { Curcumin } \\
1000 \mathrm{mg}+ \\
\text { diclofenac } \\
75 \mathrm{mg} \\
3 \text { months }\end{array}$ & PVAS & $\begin{array}{l}\mathrm{CR}+\mathrm{DI} 3.19 \\
P<.001 \text { from } \\
\quad \text { baseline }\end{array}$ & $\begin{array}{l}\mathrm{DI}+\mathrm{PL} 3.55 \\
P<.001 \text { from } \\
\quad \text { baseline }\end{array}$ & $\begin{array}{l}\text { Pain score } \\
\text { CR+DI } 81.99 \\
P<.001 \\
\text { DI+PL } 84.49 \\
P<.001\end{array}$ & $\begin{array}{l}\text { Curcumin had } \\
\text { additive } \\
\text { effects } \\
\text { with DI }\end{array}$ & $\begin{array}{l}\text { Minor hair } \\
\text { loss and } \\
\text { renal } \\
\text { distress }\end{array}$ \\
\hline $\begin{array}{l}\text { Madhu (2013), } \\
\quad 22\end{array}$ & $\begin{array}{l}\text { Turmeric } \\
\quad \text { polysaccharide } \\
\quad \text { extract } \\
500 \mathrm{mg} \\
\text { glucosamine } \\
\quad 375 \mathrm{mg} \\
2 \times / \text { day } \\
42 \text { days }\end{array}$ & $\begin{array}{l}\text { PVAS } \\
\text { WOMAC } \\
\text { for pain }\end{array}$ & $\begin{array}{l}\text { PVAS } \\
\text { TR } 19.5 \pm 17.8 \\
\text { TR+GS } 36.3 \pm 29.0 \\
\text { WOMAC } \\
\text { TR } 27.1 \pm 16.1 \\
\text { TR+GS } 36.2 \pm 27.7 \\
P<.05 \text { for all }\end{array}$ & $\begin{array}{l}\text { PVAS } \\
\text { PL } 46.0 \pm 20.8 \\
\text { GS } 29.3 \pm 20.6 \\
\text { WOMAC } \\
\text { PL } 47.9 \pm 12.6 \\
\text { GS } 34.9 \pm 19.5\end{array}$ & $\begin{array}{l}\text { CGIC } \\
\text { TR } 2.21 \pm 1.80 \\
\text { PL } 4.72 \pm 1.27 \\
\text { TR+GS } \\
\quad 3.37 \pm 2.41 \\
\quad P<.05 \\
\text { GS } 3.32 \pm 1.78 \\
P<.05\end{array}$ & $\begin{array}{l}\text { Curcumin } \\
\text { significantly } \\
\text { effective for } \\
\text { pain and } \\
\text { reduced } \\
\text { need for } \\
\text { medication }\end{array}$ & N.R. \\
\hline $\begin{array}{l}\text { Belcaro } \\
\quad(2014), 19\end{array}$ & $\begin{array}{l}\text { Curcumin } \\
\text { phospholipid } \\
+ \text { glucosamine } \\
500 \mathrm{mg} \\
\text { each } \\
1 \times / \text { day } \\
4 \text { months }\end{array}$ & $\begin{array}{l}\text { WOMAC } \\
\text { for pain }\end{array}$ & $\begin{array}{l}\mathrm{CR}+\mathrm{GS} \\
6.8 \pm 2.0, \\
\text { (compared with } \\
\quad \text { baseline) } \\
P<.05\end{array}$ & $\begin{array}{l}\mathrm{CN}+\mathrm{GS} \\
10.2 \pm 2.2 \\
\text { (compared } \\
\quad \text { with baseline) } \\
P<.05\end{array}$ & $\begin{array}{l}\text { WOMAC } \\
\quad \text { total index } \\
\text { CR+GS } \\
36.3 \pm 5.0 \\
\mathrm{CN}+\mathrm{GS} \\
64.2 \pm 7.3 \\
\text { Karnosfki index } \\
\mathrm{CR}+\mathrm{GS} \\
93.4 \pm 6.4 \\
\mathrm{CN}+\mathrm{GS} \\
79.6 \pm 6.6 \\
P<.05\end{array}$ & $\begin{array}{l}\text { CR+GS more } \\
\text { effective than } \\
\text { CN+GS }\end{array}$ & N.R. \\
\hline $\begin{array}{l}\text { Panahi (2014), } \\
17\end{array}$ & $\begin{array}{l}\text { Curcumin } \\
500 \mathrm{mg}+ \\
\text { Bioperine } \\
5 \mathrm{mg} \\
3 \times / \text { day } \\
6 \text { weeks }\end{array}$ & $\begin{array}{l}\text { WOMAC } \\
\text { for pain } \\
\text { PVAS }\end{array}$ & $\begin{array}{l}\text { WOMAC } \\
\text { CR } 37 \pm 19 \\
P<.001 \\
\text { PVAS } \\
\text { CR } 6.1 \pm 2.9 \\
P<.001\end{array}$ & $\begin{array}{l}\text { WOMAC } \\
\text { PL } 57 \pm 12 \\
\text { PVAS } \\
\text { PL } 9.4 \pm 3.4\end{array}$ & $\begin{array}{l}\text { LPFI } \\
\text { CR } 7.8 \pm 3.6 \\
\text { PL } 12 \pm 4 \\
P=.013 \\
\text { WOMAC } \\
\quad \text { total index } \\
\text { CR } 25 \pm 13 \\
\text { PL } 40.6 \pm 12.6 \\
P=.001\end{array}$ & $\begin{array}{l}\text { Results support } \\
\text { efficacy of } \\
\text { CR for OA }\end{array}$ & $\begin{array}{l}\text { CR 3, } \\
\text { PL } 4 \text { with } \\
\text { intestinal } \\
\text { symptoms }\end{array}$ \\
\hline $\begin{array}{l}\text { Nakagawa } \\
\quad(2014), 20\end{array}$ & $\begin{array}{l}\text { Curcumin } \\
180 \mathrm{mg} / \text { day } \\
8 \text { weeks }\end{array}$ & $\begin{array}{l}\text { PVAS decline } \\
\text { in score }\end{array}$ & $\begin{array}{l}\mathrm{CR}-0.40 \text { as } \\
\text { compared } \\
\text { with baseline, } \\
\text { compared with } \\
\text { PL, } P=.023\end{array}$ & $\begin{array}{l}\mathrm{PL}-0.22 \text { as } \\
\text { compared } \\
\text { to baseline }\end{array}$ & $\begin{array}{l}\text { No. of subjects } \\
\text { using pain } \\
\text { killer } \\
\text { CR } 32 \% \\
\text { PL } 60 \% \\
P=.0252\end{array}$ & $\begin{array}{l}\text { CR more } \\
\text { effective } \\
\text { than PL }\end{array}$ & $\begin{array}{l}\text { No serious } \\
\text { adverse } \\
\text { events }\end{array}$ \\
\hline $\begin{array}{l}\text { Kuptniratsaikul } \\
\text { (2014), } 18\end{array}$ & $\begin{array}{l}\text { Curcuma extract } \\
1125-1275 \mathrm{mg} \\
\text { CR/day } \\
4 \text { weeks }\end{array}$ & $\begin{array}{l}\text { WOMAC } \\
\text { for pain }\end{array}$ & $\begin{array}{l}\text { CR } 3.17 \pm 1.98 \\
P<.01 \\
\text { (compared with } \\
\quad \text { baseline) }\end{array}$ & $\begin{array}{l}\text { IB } 3.25 \pm 2.11 \\
P<.01 \text { (compared } \\
\quad \text { with baseline) }\end{array}$ & $\begin{array}{l}\text { WOMAC } \\
\text { total score } \\
\text { IB } 3.23 \pm 1.97 \\
\text { CR } 3.36 \pm 2.04\end{array}$ & $\begin{array}{l}\text { CR equally } \\
\text { effective } \\
\text { as IB but } \\
\text { fewer side } \\
\text { effects }\end{array}$ & $\begin{array}{l}\text { Both groups } \\
\text { mild } \\
\text { intestinal } \\
\text { symptoms }\end{array}$ \\
\hline
\end{tabular}

CGIC, clinician global impression of change; Karnosfki index, Karnosfki Performance Scale index; LPFI, Lequesne's pain functional index; N.R., not reported; PVAS, pain visual analogue score. 
Table 3. Risk of Bias in the Studies Included in the Systematic Review

\begin{tabular}{|c|c|c|c|c|c|c|c|c|c|}
\hline Author (year) & $\begin{array}{l}\text { Random } \\
\text { sequence } \\
\text { generation }\end{array}$ & $\begin{array}{l}\text { Allocation } \\
\text { concealment }\end{array}$ & $\begin{array}{l}\text { Patient and } \\
\text { practitioner } \\
\text { blinding }\end{array}$ & $\begin{array}{l}\text { Assessor } \\
\text { blinding }\end{array}$ & $\begin{array}{l}\text { Selective } \\
\text { outcome } \\
\text { reporting }\end{array}$ & $\begin{array}{l}\text { Reporting } \\
\text { drop out or } \\
\text { withdrawal }\end{array}$ & $\begin{array}{l}\text { Intention- } \\
\text { to-treat } \\
\text { analysis }\end{array}$ & $\begin{array}{c}\text { Other } \\
\text { potential } \\
\text { bias }\end{array}$ & Reference \\
\hline $\begin{array}{l}\text { Kuptniratsaikul } \\
\text { et al. (2009) }\end{array}$ & $\mathrm{H}$ & $\mathrm{L}$ & $\mathrm{L}$ & $\mathrm{H}$ & $\mathrm{L}$ & $\mathrm{U}$ & $\mathrm{H}$ & $\mathrm{U}$ & 16 \\
\hline $\begin{array}{l}\text { Chandran } \\
\text { et al. }(2012)\end{array}$ & $\mathrm{L}$ & $\mathrm{H}$ & $\mathrm{L}$ & $\mathrm{U}$ & $\mathrm{U}$ & $\mathrm{U}$ & $\mathrm{L}$ & $\mathrm{L}$ & 24 \\
\hline $\begin{array}{l}\text { Madhu } \\
\quad \text { et al. (2013) }\end{array}$ & $\mathrm{U}$ & $\mathrm{L}$ & $\mathrm{H}$ & $\mathrm{U}$ & $\mathrm{H}$ & $\mathrm{L}$ & $\mathrm{L}$ & $\mathrm{U}$ & 22 \\
\hline $\begin{array}{l}\text { Panahi } \\
\quad \text { et al. }(2014)\end{array}$ & $\mathrm{H}$ & $\mathrm{L}$ & $\mathrm{L}$ & $\mathrm{H}$ & $\mathrm{L}$ & $\mathrm{U}$ & $\mathrm{L}$ & $\mathrm{U}$ & 17 \\
\hline $\begin{array}{l}\text { Kuptniratsaikul } \\
\text { et al. }(2014)\end{array}$ & $\mathrm{H}$ & $\mathrm{L}$ & $\mathrm{L}$ & $\mathrm{H}$ & $\mathrm{L}$ & $\mathrm{U}$ & $\mathrm{L}$ & $\mathrm{U}$ & 18 \\
\hline $\begin{array}{l}\text { Belcaro } \\
\quad \text { et al. }(2014)\end{array}$ & $\mathrm{H}$ & $\mathrm{H}$ & $\mathrm{H}$ & $\mathrm{H}$ & $\mathrm{L}$ & $\mathrm{L}$ & $\mathrm{L}$ & $\mathrm{U}$ & 19 \\
\hline $\begin{array}{l}\text { Nakagawa } \\
\quad \text { et al. }(2014)\end{array}$ & $\mathrm{L}$ & $\mathrm{L}$ & $\mathrm{L}$ & $\mathrm{L}$ & $\mathrm{U}$ & $\mathrm{L}$ & $\mathrm{L}$ & $\mathrm{U}$ & 20 \\
\hline $\begin{array}{l}\text { Pinsornsalz } \\
\quad \text { et al. }(2012)\end{array}$ & $\mathrm{L}$ & $\mathrm{U}$ & $\mathrm{H}$ & $\mathrm{L}$ & $\mathrm{U}$ & $\mathrm{L}$ & $\mathrm{U}$ & $\mathrm{U}$ & 21 \\
\hline
\end{tabular}

$\mathrm{H}$, high risk; L, low risk, $\mathrm{U}$, uncertain.

\section{Risk of bias}

Table 3 shows the ROB assessment for the included RCTs. Among eight RCTs, four RCTs were classified as high quality ${ }^{17,18,20,23}$ and four RCTs had a moderate quality. ${ }^{16,21,22,24}$ Three studies used a proper method for randomization of the subjects such as coin flipping and computer-generated random numbers and the allocation of the groups was concealed to the subjects and also practitioners, ${ }^{17,20,24}$ but the remaining studies did not describe how the subjects were randomized and allocated. Six RCTs used blinding of patients and practitioners, ${ }^{16,18,20,22-24}$ but the remaining two RCTs did not mention their blindness to the practitioners. The drop-out rates were not high and they were not different between experimental and placebo groups. Two studies did not report the drop-out rates. ${ }^{23,24}$

\section{Outcomes}

The symptoms of arthritis, including osteoarthritis and rheumatoid arthritis, were mainly pain and inflammation and the symptoms were classified as pain, stiffness, swollenness, and movement. Most of the studies measured the severity of arthritis symptoms by pain, stiffness, and function, and the severity was scaled by PVAS and WOMAC. In four studies, the severity of pain was scaled by PVAS $^{16,20,21,24}$ and by WOMAC. ${ }^{18,23}$ Two studies measured both scales. ${ }^{17,22}$ As a result, three sets of meta-analysis were performed to compare PVAS between curcuma and placebo, ${ }^{17,22,24}$ PVAS between curcuma and pain medicine, ${ }^{16,18,22,24}$ and WOMAC between curcuma and placebo. ${ }^{17,22,23}$ Since WOMAC for pain was used for meta-analysis, six results of pain index were combined for comparing between curcumin and placebo from four studies. ${ }^{17,19,22,24}$

Since two studies ${ }^{20,21}$ did not provide means and standard deviation for PVAS or WOMAC at the end of the study, six studies were used for meta-analysis. Furthermore, since the studies measured either PVAS ${ }^{16,24}$ or WOMAC ${ }^{18,23}$ or both, ${ }^{17,22}$ and the control group was either placebo ${ }^{17,23}$ or pain medicine ${ }^{16,18}$ or both, ${ }^{22,24}$ three combinations were made for meta-analysis. Figure $2 \mathrm{~A}$ provided the pooled results of PVASs between curcumin and placebo groups from the meta-analysis of three studies. ${ }^{17,22,24}$ The PVAS was much lower in the curcumin group than in the placebo groups (overall mean differences and CI: -2.04 and -2.85 , $-1.24 ; P<.00001)$. In addition, the pooled PVAS and WOMAC pain score from five results for three studies ${ }^{17,22,24}$ were much lower in the curcuma group than in the placebo group (overall mean differences and CI: -15.26 and -26.94 , -3.77 ; $P=.009$; Fig. 2B). Figure $2 \mathrm{C}$ shows the pooled results of PVAS and WOMAC score between curcumin and pain medicine groups from five studies. ${ }^{16,18,19,22,24}$ The pooled pain indexes of PVAS and WOMAC from five studies were not significantly different between the curcumin and commercially available pain medicine such as ibuprofen, diclofenac, and glucosamine (overall mean differences and CI: -1.89 and $-4.13,0.35 ; P=.10)$. These results suggested that curcumin (about $1 \mathrm{~g}$ /day) might have similar effects as analgesic medicines.

Since the symptoms of osteoarthritis were evaluated mainly by pain, the outcome measures were quantitatively determined by the severity of pain. Most studies used PVAS or pain index in WOMAC (Table 2). Some studies used different methods: frequencies of pain killer used during the study were decreased ${ }^{17,20,22}$; the distance to walk for $6 \mathrm{~min}$, pain on level walking, pain on stars, and time spent on $100 \mathrm{~m}$ walk were not significantly different between the curcumin and ibuprofen groups. ${ }^{16,18}$ In addition to pain levels, the functional changes in the joints were important factors to determine the severity of arthritis. Functional changes can be measured on the WOMAC subscales such as morning stiffness and function, LPFI, Karnosfki Performance Scale index, and Japanese Knee Osteoarthritis Measure (JKOM). 

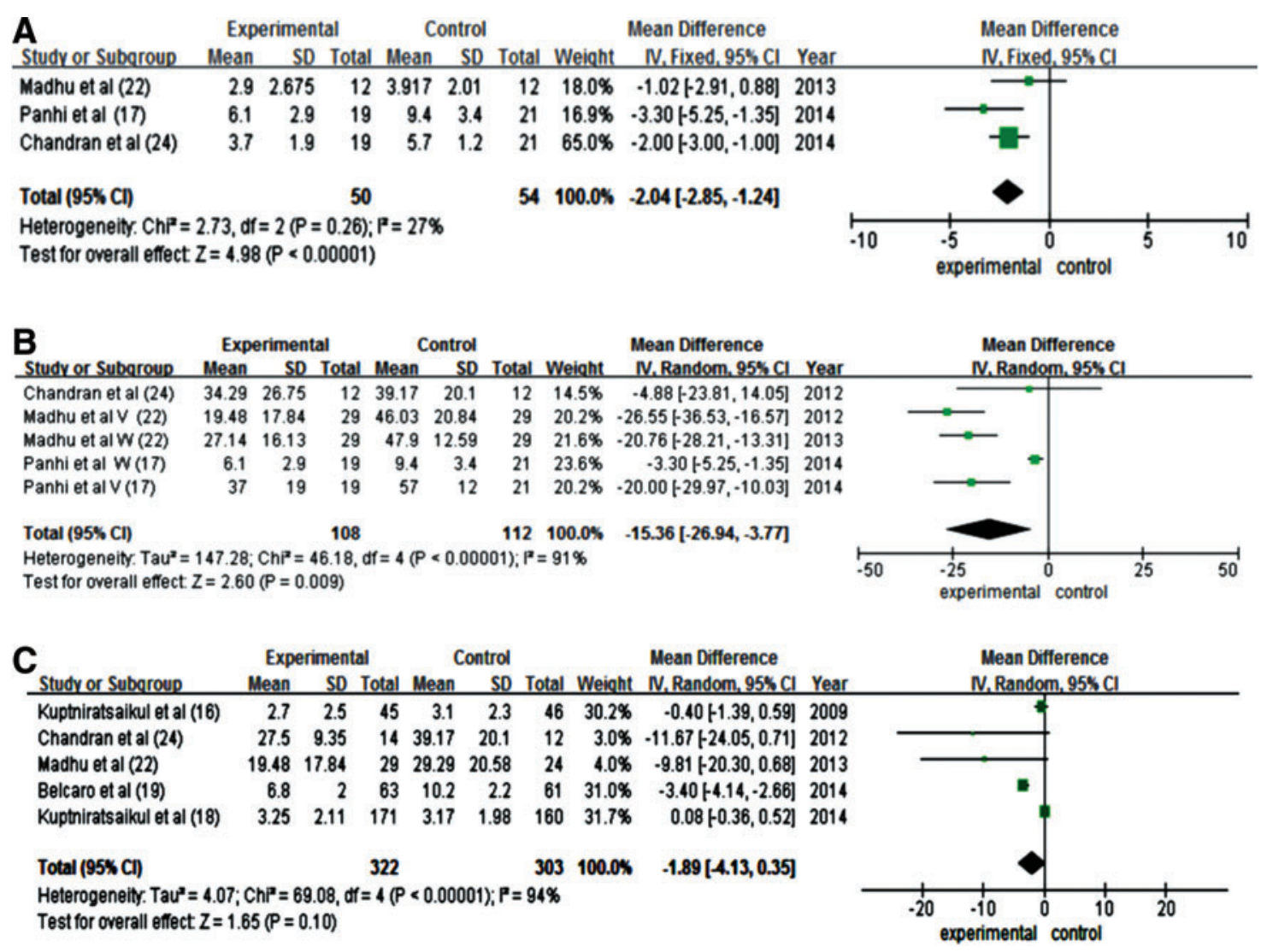

FIG. 2. Forest plot of the meta-analysis for the scores of arthritis severity. (A) Mean differences in PVAS between curcuma and placebo. (B) Mean differences in PVAS and WOMAC between curcuma and placebo. (C) Mean differences in PVAS and WOMAC between curcuma and pain medicine. Each study is identified by first author and year. PVAS, pain visual analogue score; WOMAC, Western Ontario and McMaster Universities Osteoarthritis Index. Color images available online at www.liebertpub.com/jmf

Total scores of WOMAC subscales were also lower in the curcumin group than in the placebo group. ${ }^{17,19}$ LPFI was significantly reduced in the curcumin group in comparison with the placebo group ${ }^{17}$ whereas JKOM decreased in the curcumin group more than in the placebo group, but it was not significantly different ${ }^{20}$ (Table 2). Karnosfki Performance Scale index was increased in the curcumin group in compared with the chondroitin group, indicating that the performance was improved with curcumin (Meriva). ${ }^{19}$ These results suggested that curcumin improved joint function measured by morning stiffness, movements, and other clinical assessments in comparison with the placebo group. However, it did not indicate the fundamental improvement of arthritis symptoms.

\section{Publication bias}

A symmetrical funnel plot was produced by this metaanalysis (the hollow circles in Fig. 3), which indicated there was no publication bias.

\section{Adverse events}

Six RCTs ${ }^{16-18,20,21,24}$ reported adverse effects in both the control and experimental groups. Curcumin containing herbs and curcumin showed mild fever and throat infection, gastrointestinal symptoms, hair loss, tachycardia, hypertension, and redness of tongue (Table 2). However, other control groups such as placebo and pain medicine (ibuprofen and diclofenac) also showed similar adverse effects such as gastrointestinal symptoms, itching, swelling around eyes and face, dimness of vision, unwell feeling, and renal dysfunction. Two RCTs did not report any adverse effects ${ }^{22,23}$ (Table 2). These reports indicated that the adverse symptoms were not limited to the curcumin containing herbs and curcumin up to about $1200 \mathrm{mg} /$ day. Thus, turmeric preparations and curcumin were considered to be safe at doses not exceeding $1200 \mathrm{mg} /$ day for up to 4 months.

\section{DISCUSSION}

Although the exact biochemical cause of osteoarthritis remains unknown, it is associated with inflammation in articular cartilage, which can cause abnormal joint structure in the knee and hip and it is accompanied with pain. The most common treatments are analgesics and NSAIDs. ${ }^{5}$ However, the drugs have serious adverse events in the gastrointestinal tract and cardiovascular system. ${ }^{6}$ Therefore, herbal treatments that can mitigate the pain and inflammation have been investigated as potential primary or adjunct therapies for 

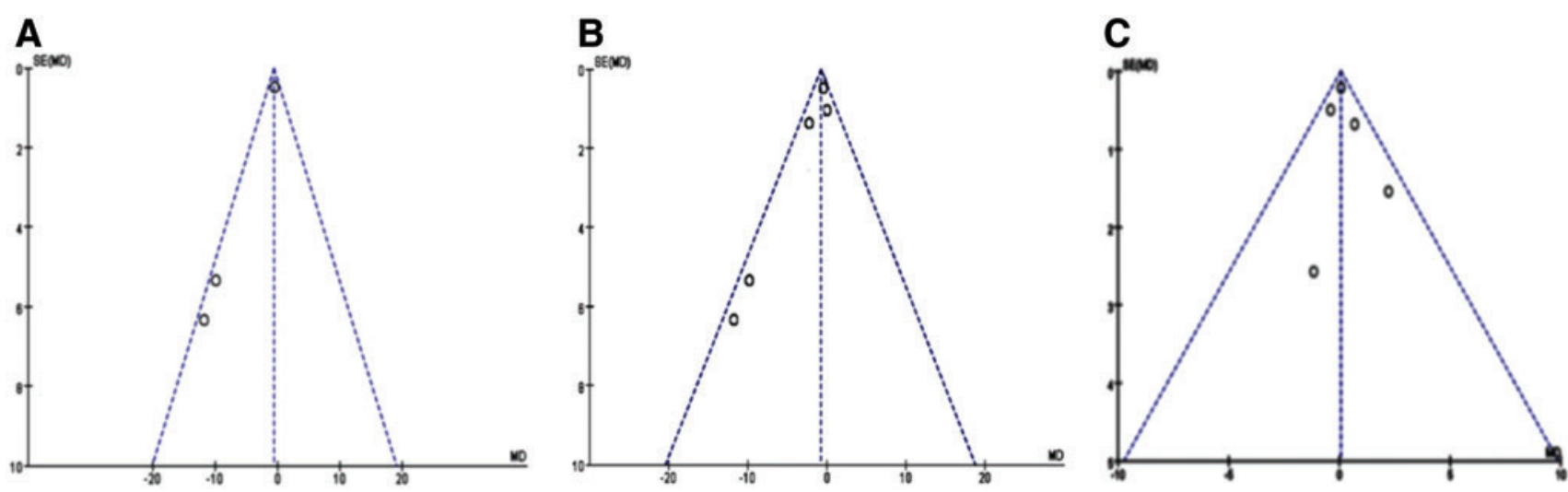

FIG. 3. Funnel plot of the meta-analysis for the scores of arthritis severity. (A) Three results to measure PVAS as arthritis severity between curcuma and place. (B) Four results to measure and PVAS and WOMAC as arthritis severity between curcuma and placebo. (C) Five results to measure PVAS and WOMAC as arthritis severity between curcuma and pain medicine. The hollow circles represent the studies in the metaanalysis. Color images available online at www.liebertpub.com/jmf

relieving arthritis symptoms. This systematic review and meta-analysis provided scientific evidence that $8-12$ weeks of standardized turmeric extracts (typically $1000 \mathrm{mg}$ /day of curcumin) treatment can reduce arthritis symptoms (mainly pain and inflammation-related symptoms) and result in similar improvements of the symptoms as ibuprofen and diclofenac sodium. Therefore, turmeric extracts and curcumin can be cautiously recommended for alleviating the symptoms of arthritis, especially osteoarthritis. However, the sample sizes (45-124) of the studies included in this review were insufficient to be conclusive, and some studies represented moderate quality. Further high-quality RCT studies with more subjects are needed to confirm the therapeutic efficacy of turmeric and curcumin for arthritis.

The article by Pinsornsak and Niempoog ${ }^{21}$ was not included in the meta-analyses because its design did not permit its data to be merged with any of the other studies. That RCT was a comparison of diclofenac $(75 \mathrm{mg} /$ day) with or without curcumin $(1000 \mathrm{mg} /$ day). Both groups made significant improvements over the 3-month course of the study, but although the group that included curcumin seemed to improve more, there was no significant differences between groups. Since diclofenac is an NSAID, it is possible that its mechanisms of action are similar to those of curcumin and the redundancy of action resulted in little additional benefit. The authors also suggested that the lack of statistical significance might have been influenced by the drop-out rate of $9 \%$ due to difficulty in traveling for follow up in the rural area. They also suggested that the dose may have been too low; however, other studies included in this review found significant improvements at lower dosages. However, the design of this study did not permit a determination of the effectiveness of curcumin alone.

The study by Madhu et $a .^{22}$ was unique in using a turmeric extract that contained only polar substances, especially polysaccharides, and no curcumin. This study had four groups: placebo, turmeric, chondroitin sulfate, and turmeric plus chondroitin sulfate. Turmeric and chondroitin sulfate both provided significant benefits by both PVAS and
WOMAC score, with turmeric performing significantly better. However, combining turmeric and chondroitin provided no added benefit, which may be due to redundant effects as already suggested for curcumin and diclofenac. The most important contribution of this study, however, may be that it demonstrated potent anti-inflammatory and/or analgesic benefits for turmeric components other than curcumin.

Osteoarthritis is exacerbated by the activation of NF- $\kappa \mathrm{B}$, which is initiated by a host of stress-related stimuli, including proinflammatory cytokines, excessive mechanical stress, and extracellular matrix degradation products., ${ }^{4,30}$ These actions reduce the amount of articular cartilage in the joints and wear out the bones near the joints to induce pain and difficulty in movements. As a result, osteoarthritis treatment focuses on relieving pain and swelling, improving joint mobility and stiffness, increasing the strength of the joints, and minimizing the disabling effects of the disease. ${ }^{31}$ Thus, the severity of arthritis is mostly measured by PVAS and WOMAC as symptomatic end-point results in RCTs.

The approved drugs commonly used to treat arthritis, such as NSAIDs, have adverse effects, and alternative treatments have been investigated. NSAIDs increase the risk of gastrointestinal bleeding, vascular adverse events, and allergic responses. ${ }^{32}$ Symptomatic slow-acting drugs for osteoarthritis such as glucosamine sulfate, glucosamine hydrochloride, chondroitin sulfate, hyaluronic acid, avocado soybean unsaponifiables, and diacerein are common alternative medicines for treating osteoarthritis symptoms. ${ }^{33-36}$ In systematic reviews, glucosamine and diacerein were found to reduce pain but did not alleviate joint space narrowing. ${ }^{33,36}$ In addition, they also caused some gastrointestinal and metabolic disturbances, although the adverse effects were less than NSAIDs. ${ }^{37}$ People with impaired glucose tolerance or insulin resistance are more likely to exhibit severely impaired glucose metabolism with glucosamine treatment for osteoarthritis. ${ }^{33,37}$ Therefore, these drugs cannot be used for long-term treatment, although osteoarthritis is a chronic long-term disease. Herbal medicine 
is often recommended for osteoarthritis treatment. Herbal and complementary therapies are safer to use and can be taken for longer periods, but they are also subject to widespread advertising and attractive, but unsubstantiated, claims that are often made for many natural products. Promising therapeutic agents for treating osteoarthritis can be compounds that block NF- $\kappa$ B signaling. ${ }^{38}$ Several candidates for naturally occurring NF- $\kappa \mathrm{B}$ inhibitors are phytochemicals such as flavonoids and catechins from green tea, rosehip, curcumin, and resveratrol. ${ }^{38,39}$

Turmeric ( $C$. longa) has a long history of safe use as food and it has long been used as in anti-inflammatory treatment in traditional Chinese and Ayurvedic medicine. ${ }^{30}$ Turmeric contains a yellow-pigmented fraction that mainly consists of curcuminoids. The principal ingredient of curcuminoids is curcumin, which is reported to have beneficial effects on osteoarthritis, type 2 diabetes, and dyslipidemia due to its antioxidant and anti-inflammatory activities. However, the systemic bioavailability of curcumin is known to be poor. ${ }^{40}$ Several studies have reported that curcumin concentrations are extremely low or nonexistent in serum and tissues at 1,2, 3 , and $4 \mathrm{~h}$ after taking a single oral dose of $500-8000 \mathrm{mg}$ in humans, and also after long-term oral administration of 440-2200 mg curcumin or curcuma extracts per day. ${ }^{41-43}$ This is associated with the low stability of curcumin in aqueous solution at physiological $\mathrm{pH}$, and within $30 \mathrm{~min}$, curcumin is degraded into trans-6-(4'-hydroxy-3'-methoxyphenyl)-2,4dioxo-5-hexenal, ferulic aldehyde, ferulic acid, feruloyl methane, vanillin, vanillic acid, and other dimerization end products. ${ }^{44,45}$ The metabolites of curcumin are present in high concentrations in the circulation after curcumin consumption. These curcumin metabolites may be responsible for the antiinflammatory and antioxidant activities that reduce the symptoms of metabolic diseases including osteoarthritis. ${ }^{44,45}$ However, Gupta et al. reported that curcumin is low but detectable in the circulation as the forms of glucuronide and sulfate conjugates in the patients with oral consumption of $8 \mathrm{~g} /$ day curcumin for more than 2 months. ${ }^{46}$ Thus, curcumin itself can be a therapeutic agent for relieving arthritis.

Korea Food and Drug Safety administration has declared turmeric roots as "generally regarded as safe." Turmeric and curcumin have been found to be safe and tolerable in human clinical trials and systematic reviews. ${ }^{47}$ No long-term studies with curcumin have revealed toxic or adverse effects. ${ }^{48}$ However, some clinical studies in humans with high doses (8-12 g) of curcumin have shown a few side effects, with some subjects reporting mild nausea or diarrhea. ${ }^{49}$ The studies used in this systematic review and meta-analyses used several types of turmeric and curcumin preparations and all appeared to provide efficacy for treating arthritis.

Recently, high doses of curcumin was found to alter iron metabolism by chelating iron and suppressing the protein hepcidin, potentially causing iron deficiency in susceptible patients. ${ }^{40}$ However, overall, the dosage required to improve osteoarthritis was less than $2000 \mathrm{mg} /$ day and this dosage did not show any noticeable adverse effects in this review. Thus, turmeric and curcumin can be safely used as a therapeutic agent for osteoarthritis.
To the best of our knowledge, this is the first systematic review and meta-analysis of RCTs on the effectiveness of turmeric extract or curcumin for arthritis. Although the present meta-analysis of RCTs suggested that oral administration of curcumin reduced arthritis symptoms, as measured by PVAS and WOMAC, as much as pain medicine, it is difficult to recommend curcumin and turmeric as a good therapeutic agent for arthritis due to the limitations of the RCT studies included in this systematic review. The limitations of the studies are as follows: first, the number of RCTs $(n=8)$ and sample sizes $(n=45-124)$ of the primary studies are low. RCTs had either a placebo control or pain medicine control, and they also utilized different end-point measurements such as PVAS and/or WOMAC. Thus, total sample size of each meta-analysis was low: PVAS for curcuma and placebo was 60 curcuma and 62 placebo; WOMAC score for curcuma and placebo was 308 curcuma and 291 placebo; PVAS for curcuma and pain medicine was 258 curcuma and 242 pain medicine. Furthermore, there were various turmeric preparations, some designed to increase absorption, that complicate drawing firm conclusions about the most effective preparation method and dose. However, this is also a strength of the study because it demonstrates that turmeric contains multiple functional compounds and their metabolites that have efficacy for arthritis. In addition, the RCTs included in the systematic review had overall lowto-moderate ROB. Four RCTs were classified as high quality ${ }^{17,18,20,23}$ and four RCTs had a moderate quality. ${ }^{16,21,22,24}$ Some studies did not report randomization of the subjects and allocation of the groups, ${ }^{17,20,24}$ whereas two RCTs did not mention their blindness to the practitioners. ${ }^{17,21}$ In addition, two RCTs did not report drop-out rates and reasons for withdrawals from the trials. ${ }^{23,24}$ However, it is difficult to detect bias resulting from authors not publishing negative results that are considered uninteresting, so there is still some possibility of publication bias.

In conclusion, although the studies used in this metaanalysis do not have sufficient number of subjects to permit a definitive recommendation for the use of curcumin as a treatment for arthritis, they do provide a compelling justification for its use as a dietary adjunct to conventional therapy. Furthermore, they also provide sufficient evidence to support larger clinical trials that could eventually lead to its acceptance as a standard therapy for many forms of arthritis and possibly other inflammatory conditions.

\section{ACKNOWLEDGMENT}

This work was supported by a grant from the Korea Institute of Oriental Medicine (grant no. K16291).

\section{AUTHOR DISCLOSURE STATEMENT}

James W. Daily is the President of Daily Manufacturing, Inc. that manufactures dietary supplements. The other authors have no conflicts of interest. 


\section{REFERENCES}

1. Johnson VL, Hunter DJ: The epidemiology of osteoarthritis. Best Pract Res Clin Rheumatol 2014;28:5-15.

2. Goldring SR: Pathogenesis of bone and cartilage destruction in rheumatoid arthritis. Rheumatology (Oxford) 2003;42 Suppl 2: ii11-ii16.

3. Vos T, Flaxman AD, Naghavi M, et al.: Years lived with disability (YLDs) for 1160 sequelae of 289 diseases and injuries 1990-2010: A systematic analysis for the Global Burden of Disease Study 2010. Lancet 2012;380:2163-2196.

4. Marcu KB, Otero M, Olivotto E, Borzi RM, Goldring MB: NF-kappaB signaling: Multiple angles to target OA. Curr Drug Targets 2010;11:599-613.

5. Suokas AK, Sagar DR, Mapp PI, Chapman V, Walsh DA: Design, study quality and evidence of analgesic efficacy in studies of drugs in models of OA pain: A systematic review and a metaanalysis. Osteoarthritis Cartilage 2014;22:1207-1223.

6. Schnitzer TJ: Update on guidelines for the treatment of chronic musculoskeletal pain. Clin Rheumatol 2006;25 Suppl 1:S22-S29.

7. Funk JL, Frye JB, Oyarzo JN, et al.: Efficacy and mechanism of action of turmeric supplements in the treatment of experimental arthritis. Arthritis Rheum 2006;54:3452-3464.

8. Henrotin Y, Lambert C, Couchourel D, Ripoll C, Chiotelli E: Nutraceuticals: Do they represent a new era in the management of osteoarthritis? - a narrative review from the lessons taken with five products. Osteoarthritis Cartilage 2011;19:1-21.

9. Lakhan SE, Ford CT, Tepper D: Zingiberaceae extracts for pain: A systematic review and meta-analysis. Nutr $J$ 2015;14:50.

10. Goel A, Kunnumakkara AB, Aggarwal BB: Curcumin as "Curecumin": From kitchen to clinic. Biochem Pharmacol 2008;75: 787-809.

11. Nurtjahja-Tjendraputra E, Ammit AJ, Roufogalis BD, Tran VH, Duke CC: Effective anti-platelet and COX-1 enzyme inhibitors from pungent constituents of ginger. Thromb Res 2003;111:259265.

12. Daily JW, Zhang X, Kim DS, Park S: Efficacy of ginger for alleviating the symptoms of primary dysmenorrhea: A systematic review and meta-analysis of randomized clinical trials. Pain Med 2015;16:2243-2255.

13. Peddada KV, Peddada KV, Shukla SK, Mishra A, Verma V: Role of curcumin in common musculoskeletal disorders: A review of current laboratory, translational, and clinical data. Orthop Surg 2015;7:222-231.

14. Appelboom T, Maes N, Albert A: A new curcuma extract (flexofytol(R)) in osteoarthritis: Results from a belgian real-life experience. Open Rheumatol J 2014;8:77-81.

15. Prasad S, Gupta SC, Tyagi AK, Aggarwal BB: Curcumin, a component of golden spice: From bedside to bench and back. Biotechnol Adv 2014;32:1053-1064.

16. Kuptniratsaikul V, Thanakhumtorn S, Chinswangwatanakul $\mathrm{P}$, Wattanamongkonsil L, Thamlikitkul V: Efficacy and safety of Curcuma domestica extracts in patients with knee osteoarthritis. J Altern Complement Med 2009;15:891-897.

17. Panahi Y, Rahimnia AR, Sharafi M, Alishiri G, Saburi A, Sahebkar A: Curcuminoid treatment for knee osteoarthritis: A randomized double-blind placebo-controlled trial. Phytother Res 2014;28:1625-1631.

18. Kuptniratsaikul V, Dajpratham $\mathrm{P}$, Taechaarpornkul $\mathrm{W}$, et al.: Efficacy and safety of Curcuma domestica extracts compared with ibuprofen in patients with knee osteoarthritis: A multicenter study. Clin Interv Aging 2014;9:451-458.

19. Belcaro G, Dugall M, Luzzi R, et al: Meriva(R)+glucosamine versus condroitin+glucosamine in patients with knee osteoarthritis: An observational study. Eur Rev Med Pharmacol Sci 2014; 18:3959-3963.

20. Nakagawa Y, Mukai S, Yamada S, et al:: Short-term effects of highly-bioavailable curcumin for treating knee osteoarthritis: A randomized, double-blind, placebo-controlled prospective study. J Orthop Sci 2014;19:933-939.

21. Pinsornsak P, Niempoog S: The efficacy of Curcuma longa L. extract as an adjuvant therapy in primary knee osteoarthritis: A randomized control trial. J Med Assoc Thai 2012;95 Suppl 1: S51-S58.

22. Madhu K, Chanda K, Saji MJ: Safety and efficacy of Curcuma longa extract in the treatment of painful knee osteoarthritis: A randomized placebo-controlled trial. Inflammopharmacology 2013; 21:129-136.

23. Belcaro G, Cesarone MR, Dugall M, et al.: Efficacy and safety of Meriva(R), a curcumin-phosphatidylcholine complex, during extended administration in osteoarthritis patients. Altern Med Rev 2010;15:337-344.

24. Chandran B, Goel A: A randomized, pilot study to assess the efficacy and safety of curcumin in patients with active rheumatoid arthritis. Phytother Res 2012;26:1719-1725.

25. Altman RD: Criteria for the classification of osteoarthritis of the knee and hip. Scand J Rheumatol Suppl 1987;65:31-39.

26. Bellamy N: WOMAC: a 20-year experiential review of a patientcentered self-reported health status questionnaire. J Rheumatol 2002;29:2473-2476.

27. Migliore A, Granata M, Tormenta S, et al:: Hip viscosupplementation under ultra-sound guidance riduces NSAID consumption in symptomatic hip osteoarthritis patients in a long follow-up. Data from Italian registry. Eur Rev Med Pharmacol Sci 2011;15:25-34.

28. Higgins JP, Altman DG, Gotzsche PC, et al.: The Cochrane Collaboration's tool for assessing risk of bias in randomised trials. BMJ 2011;343:d5928.

29. Higgins JP, Thompson SG, Deeks JJ, Altman DG: Measuring inconsistency in meta-analyses. BMJ 2003;327:557-560.

30. He Y, Yue Y, Zheng X, Zhang K, Chen S, Du Z: Curcumin, inflammation, and chronic diseases: How are they linked? Molecules 2015;20:9183-9213.

31. Moyer RF, Ratneswaran A, Beier F, Birmingham TB: Osteoarthritis year in review 2014: Mechanics-Basic and clinical studies in osteoarthritis. Osteoarthritis Cartilage 2014;22:1989-2002.

32. Mukherjee D, Nissen SE, Topol EJ: Risk of cardiovascular events associated with selective COX-2 inhibitors. JAMA 2001; 286:954-959.

33. Towheed TE, Maxwell L, Anastassiades TP, et al.: Glucosamine therapy for treating osteoarthritis. Cochrane Database Syst Rev 2005:Cd002946.

34. Rintelen B, Neumann K, Leeb BF: A meta-analysis of controlled clinical studies with diacerein in the treatment of osteoarthritis. Arch Intern Med 2006;166:1899-1906.

35. Pavelka K: A comparison of the therapeutic efficacy of diclofenac in osteoarthritis: A systematic review of randomised controlled trials. Curr Med Res Opin 2012;28:163-178.

36. Fidelix TS, Macedo CR, Maxwell LJ, Fernandes Moca Trevisani V: Diacerein for osteoarthritis. Cochrane Database Syst Rev 2014;2:Cd005117. 
37. Dostrovsky NR, Towheed TE, Hudson RW, Anastassiades TP: The effect of glucosamine on glucose metabolism in humans: A systematic review of the literature. Osteoarthritis Cartilage 2011; 19:375-380.

38. Mobasheri A, Henrotin Y, Biesalski HK, Shakibaei M: Scientific evidence and rationale for the development of curcumin and resveratrol as nutraceutricals for joint health. Int J Mol Sci 2012; 13:4202-4232.

39. Clutterbuck AL, Asplin KE, Harris P, Allaway D, Mobasheri A: Targeting matrix metalloproteinases in inflammatory conditions. Curr Drug Targets 2009;10:1245-1254.

40. Shen L, Liu CC, An CY, Ji HF: How does curcumin work with poor bioavailability? Clues from experimental and theoretical studies. Sci Rep 2016;6:20872.

41. Sharma RA, McLelland HR, Hill KA, et al.: Pharmacodynamic and pharmacokinetic study of oral Curcuma extract in patients with colorectal cancer. Clin Cancer Res 2001;7:1894-1900.

42. Anand P, Kunnumakkara AB, Newman RA, Aggarwal BB: Bioavailability of curcumin: Problems and promises. Mol Pharm 2007;4:807-818.

43. Lao CD, Ruffin MT 4th, Normolle D, et al.: Dose escalation of a curcuminoid formulation. BMC Complement Altern Med 2006;6:10.
44. Heger M, van Golen RF, Broekgaarden M, Michel MC: The molecular basis for the pharmacokinetics and pharmacodynamics of curcumin and its metabolites in relation to cancer. Pharmacol Rev 2014;66:222-307.

45. Wang YJ, Pan MH, Cheng AL, et al:: Stability of curcumin in buffer solutions and characterization of its degradation products. J Pharm Biomed Anal 1997;15:1867-1876.

46. Gupta SC, Patchva S, Koh W, Aggarwal BB: Discovery of curcumin, a component of golden spice, and its miraculous biological activities. Clin Exp Pharmacol Physiol 2012;39:283299.

47. Posadzki P, Watson LK, Ernst E: Adverse effects of herbal medicines: An overview of systematic reviews. Clin Med 2013; 13:7-12.

48. Aggarwal BB, Harikumar KB: Potential therapeutic effects of curcumin, the anti-inflammatory agent, against neurodegenerative, cardiovascular, pulmonary, metabolic, autoimmune and neoplastic diseases. Int J Biochem Cell Biol 2009;41: 40-59.

49. Fan X, Zhang C, Liu DB, Yan J, Liang HP: The clinical applications of curcumin: Current state and the future. Curr Pharm Des 2013;19:2011-2031. 